\title{
Pesca de pequena escala e a gestão patrimonial: o caso da pesca da tainha no litoral paranaense ${ }^{1}$
}

\section{Small-Scale Fisheries and Common Property Resource Management: the Case of the Mullet Fishery in Paraná State, Brazil}

\author{
Luciana PINHEIRO* \\ Paulo da Cunha LANA** \\ José Milton ANDRIGUETTO FILHO*** \\ Natalia HANAZAKI****
}

\begin{abstract}
RESUMO
O arrastão de praia, que tem na tainha seu principal alvo, é uma das mais antigas formas de pesca ainda praticadas no litoral do Paraná. Este artigo aborda aspectos da gestão patrimonial dessa pescaria, com ênfase sobre as causas de seu declínio, segundo a percepção dos próprios pescadores. A abordagem foi etnoecológica, empregando observação direta, aprendizado vivenciado e entrevistas semiestruturadas com 13 informantes especialistas. Estes não consideraram que a prática leve à sobre-exploração do recurso, mas mostraram um senso de conservação baseado em considerações econômicas. Uma mentalidade conservacionista surgiu muito recentemente, em decorrência das constatações empíricas de redução da abundância de peixes. A inserção de novas tecnologias de pesca mais produtivas e rentáveis contribuiu para as mudanças nos regimes de acesso aos recursos (caracterizadas principalmente pelo desrespeito às regras informais de uso). Uma ruptura de valores fomentou a competição, que se reflete no aumento do esforço de pesca, na preferência por práticas individuais, no uso de apetrechos considerados predatórios e na pesca em regiões e períodos proibidos, levando ao declínio da atividade. As características particulares do arrastão de praia, de ser uma pesca coletiva, que desenvolve laços e valores sociais importantes para o espírito comunitário, como coletividade, colaboração, respeito às normas sociais, reunião e partilha, precisam ser incorporadas à agenda de preocupações dos órgãos gestores. Para tanto, é necessária a participação dos usuários no processo de gestão, o que também permitiria considerar devidamente a história dessa prática e a projeção de cenários que os pescadores mais velhos conseguem fazer, baseados em suas experiências e nas profundas mudanças socioambientais pelas quais passaram.
\end{abstract}

\footnotetext{
${ }^{1}$ Partes deste texto já foram apresentadas em seminários e congressos científicos e em Pinheiro (2007).

"Bióloga, Doutora em Meio Ambiente e Desenvolvimento (Universidade Federal do Paraná). E-mail: lucianapbio@gmail.com

"* Oceanógrafo biólogo, Doutor em Ciências (Universidade de São Paulo). Centro de Estudos do Mar - CEM, Universidade Federal do Paraná - UFPR. Email: lana@ufpr.br

*** Oceanógrafo, Doutor em Meio ambiente e Desenvolvimento. Professor do Departamento de Zootecnia da Universidade Federal do Paraná. Email: jmandri@ufpr.br

"*** Doutora em Ecologia pela Universidade Estadual de Campinas. Professora Adjunta IV, Departamento de Ecologia e Zoologia, Universidade Federal de Santa Catarina.Email: natalia@ccb.ufsc.br
} 
A incorporação da dimensão simbólica ou não material de apropriação do recurso é, neste sentido, uma condição necessária à gestão sustentável da atividade.

Palavras-chave: pesca artesanal; arrastão de praia; tainha; sul do Brasil; recursos de uso comum.

\begin{abstract}
The beach seine, with mullet as its main target, is one of the oldest fishery practices in Paraná, Brazil. This article focuses on the common property management of this fishery, with emphasis on the causes of its decline, as perceived by the fishermen themselves. The approach was ethnoecological, employing direct observation, experienced learning and semi-structured interviews with 13 local experts. They did not consider that the practice leads to over-exploitation of the resource, but showed a sense of conservation based on economic considerations. A conservationist mentality emerged more recently as a result of the empirical realization of reduced fish abundance. The introduction of new, more productive and profitable fishing techniques contributed to changes in the regimes of access to resources (mainly characterized by disregard for the informal rules of usage). A breakdown of values fostered competition, leading to an increase in fishing effort, adoption of individual practices, use of gears considered predatory, and fishing in prohibited areas and periods. That, in turn, resulted in the decline of the activity. The particular characteristics of the beach seine, namely, a group practice that fosters the development of social ties and important values to the sense of community, such as collectivity, collaboration, respect for social norms, sharing and re-union, must be incorporated into the agenda of management agencies. Doing so requires the participation of users in the management process, which would also allow due consideration of the history of this practice and the projection of scenarios that older fishermen can do, based on their experiences and the deep social-environmental changes to which they were submitted. The knowledge of beliefs, feelings and behaviors of different generations of fishermen regarding nature is a necessary condition for the management and sustainability of the activity.
\end{abstract}

Key-words: small-scale fisheries; Southern Brazil; mullet; common property resources; beach seine.

\section{Introdução}

O presente artigo objetiva descrever aspectos importantes à gestão da pesca de pequena escala, com base na gestão patrimonial observada na pesca do arrastão de praia, particularmente da tainha, no litoral do Paraná, considerando o declínio de sua prática face às mudanças nas formas de uso e apropriação do recurso.

O enfoque da gestão patrimonial prefigura estratégias de desenvolvimento baseadas nas maneiras com que uma população tradicional percebe, valora, usa, acessa e controla o acesso aos recursos naturais presentes no seu ambiente (OLLAGNON, 1997; MONTGOLFIER; NATALI, 1997). Acena, portanto, para a necessidade de políticas ambientais que considerem as "regras sociais que governam a apropriação e os usos que diferentes atores sociais fazem da base de recursos naturais, do espaço e do habitat, em contextos históricos [e culturais] específicos" (VIEIRA, 1995, p. 296-297).
Esse enfoque pretende criar subsídios para a solução mais equilibrada de problemas complexos da gestão da natureza, mediante visão analítica, sistêmica e integrada, satisfazendo o indivíduo e a sociedade (OLLAGNON, 1997, p. 199; VIEIRA; WEBER, 1997). Para tanto, todos os atores da sociedade devem ser gestores patrimoniais dos recursos e ambientes naturais (OLLAGNON, 1997, p. 199-200), favorecendo o planejamento participativo, contextualizado e democrático de estratégias integradas de desenvolvimento (VIEIRA, 1995, p. 298-299). Nesse sentido, a gestão patrimonial também contribui para a compreensão das formas de usos e apropriação dos recursos naturais.

A abordagem patrimonial considera o grande número de atores sociais, as representações e motivações diferenciadas e a transmissão intergeracional da qualidade dos recursos e dos ecossistemas (VINATEA, 2000, p. 17-18). A definição e delimitação dos usuários, bem como a regulação das modalidades de uso e apropriação dos recursos pesqueiros, constituem os principais desafios à instituição 
de novos sistemas de gestão patrimonial desses recursos (REBOUÇAS et al., 2006, p. 86).

Considerando que, além das necessidades materiais, há necessidades intangíveis, como autodeterminação, participação política, desenvolvimento cultural, autorrealização existencial etc. (VIEIRA, 2005, p. 346-348), a abordagem da gestão patrimonial é a que melhor se relaciona com a gestão participativa. Conforme Berkes et al. (2006, p. 24$25,62,110)$ propõem, a gestão baseada na comunidade e compartilhada trata o desenvolvimento comunitário como parte integral da gestão dos recursos pesqueiros. As metodologias interdisciplinares e das ciências sociais, o uso do conhecimento dos pescadores sobre ecologia local e a pesquisa de diagnóstico rural participativo são uma tendência global da gestão pública e do desenvolvimento em escalas local, nacional e internacional e constituem elementos para se alcançar bons resultados na gestão dos recursos. Não obstante, os benefícios da gestão participativa, mesmo sendo conhecidos há décadas pelos cientistas que trabalham com o tema do desenvolvimento social, apenas recentemente foram reconhecidos no âmbito da gestão dos recursos pesqueiros (BERKES et al., 2006, p. 152).

$\mathrm{O}$ arrastão de praia, por sua vez, incluindo a captura sazonal da tainha por meio dessa arte de pesca, foi uma importante prática de reprodução social e produção econômica no litoral su-sudeste brasileiro (BECK, 1989; DIEGUES, 2004), mas Andriguetto Filho (1998, não publicado; 1999) e Corrêa et al. (1993) identificaram o declínio de sua prática ao longo do litoral paranaense. Paradoxalmente, ela persiste em alguns pontos.

Com base nas contribuições de Andriguetto Filho (1998, não publicado), Beck (1989) e Diegues (2004) foi possível estabelecer como pressuposto inicial que, mais do que os beneficios econômicos, são o conhecimento tradicional e as representações não materiais dele derivadas que mantêm a prática do arrastão de praia no litoral sudeste e sul do Brasil e no litoral do Paraná, em particular.

Assim, foi possível formular o seguinte problema de pesquisa: Quais são as causas, segundo a percepção dos pescadores do arrastão de praia, donos de rede, com mais de 50 anos de idade, do declínio do arrastão de praia e que repercussões esse fenômeno traz para o sistema pesqueiro do litoral do Paraná?

Partindo dessa problematização, foram analisadas três hipóteses inter-relacionadas que poderiam explicar o processo de declínio da pesca de arrastão de praia no litoral do Paraná:

1) o modo de conservação local (etnoconservação) influencia a continuidade dos arrastões de praia e, indiretamente, a manutenção dos estoques pesqueiros;

2) a inserção de novas tecnologias de pesca mais produtivas e rentáveis contribui para o declínio dos arrastões de praia;

3 ) as mudanças nos regimes de acesso aos recursos pesqueiros geraram desestruturação social, promovendo o declínio dos arrastões de praia.

Foram entrevistados 13 informantes, pescadores e ex-pescadores do arrastão de praia, considerados especialistas nessa pesca, além de duas mulheres, também consideradas especialistas, e um jovem, pertencentes às comunidades pesqueiras de Barra do Saí-Guaçu, Prainha, Caiobá, Ipanema, Shangri-lá, Guapê, Barranco, Pontal do Sul, Maciel, Ilha do Mel ou Barra do Ararapira, localizadas no litoral paranaense. O trabalho de campo incluiu entrevistas semiestruturadas, observações diretas e participações do tipo aprendizado vivenciado, além de registros fotográficos e fílmicos, no período não contínuo entre maio de 2005 e junho de 2007. O estudo foi orientado pelo referencial teórico-metodológico da etnoecologia ${ }^{2}$. Segundo Toledo (1992), a etnoecologia investiga como os recursos naturais são vistos, manejados e apropriados pelos agrupamentos humanos. Para Nazarea (2002), é "um modo de olhar" para as relações entre os seres humanos e o mundo natural, com ênfase no papel que tem a cognição em moldar comportamentos. Já Marques (2001) considera que a "Etnoecologia é o estudo das interações entre a humanidade e o resto da ecosfera [...]. Sua ênfase, pois, deve ser na diversidade biocultural e o seu objetivo principal, a integração entre o conhecimento ecológico tradicional e o conhecimento ecológico científico" (MARQUES, 2001, p. 49, sem grifos no original). A etnoecologia, portanto, enfatiza as interações entre pessoas e componentes do mundo natural, mediadas por suas percepções e analisadas de modo integrado com o conhecimento acadêmico.

A respeito da caracterização geográfica do local de estudo, o litoral paranaense está incluído na costa sul do Brasil (MAACK, 1968). É o macrossetor litorâneo mais diversificado e acidentado do país (Ab’SABER, 2001). Com uma extensão aproximada de $105 \mathrm{~km}$ e uma área de cerca de $6.600 \mathrm{~km}^{2}$, está localizado entre as latitudes $25^{\circ} \mathrm{e}$ $26^{\circ} \mathrm{S}$ e longitudes $48^{\circ}$ e $49^{\circ} \mathrm{W}$ (MARONE et al., 2002, p. 4-6; SOARES et al., 1997, p. 1-5) (Figura 1).

${ }^{2}$ Veja-se mais sobre a abordagem etnoecológica adotada neste estudo em Pinheiro et al. (2009). 

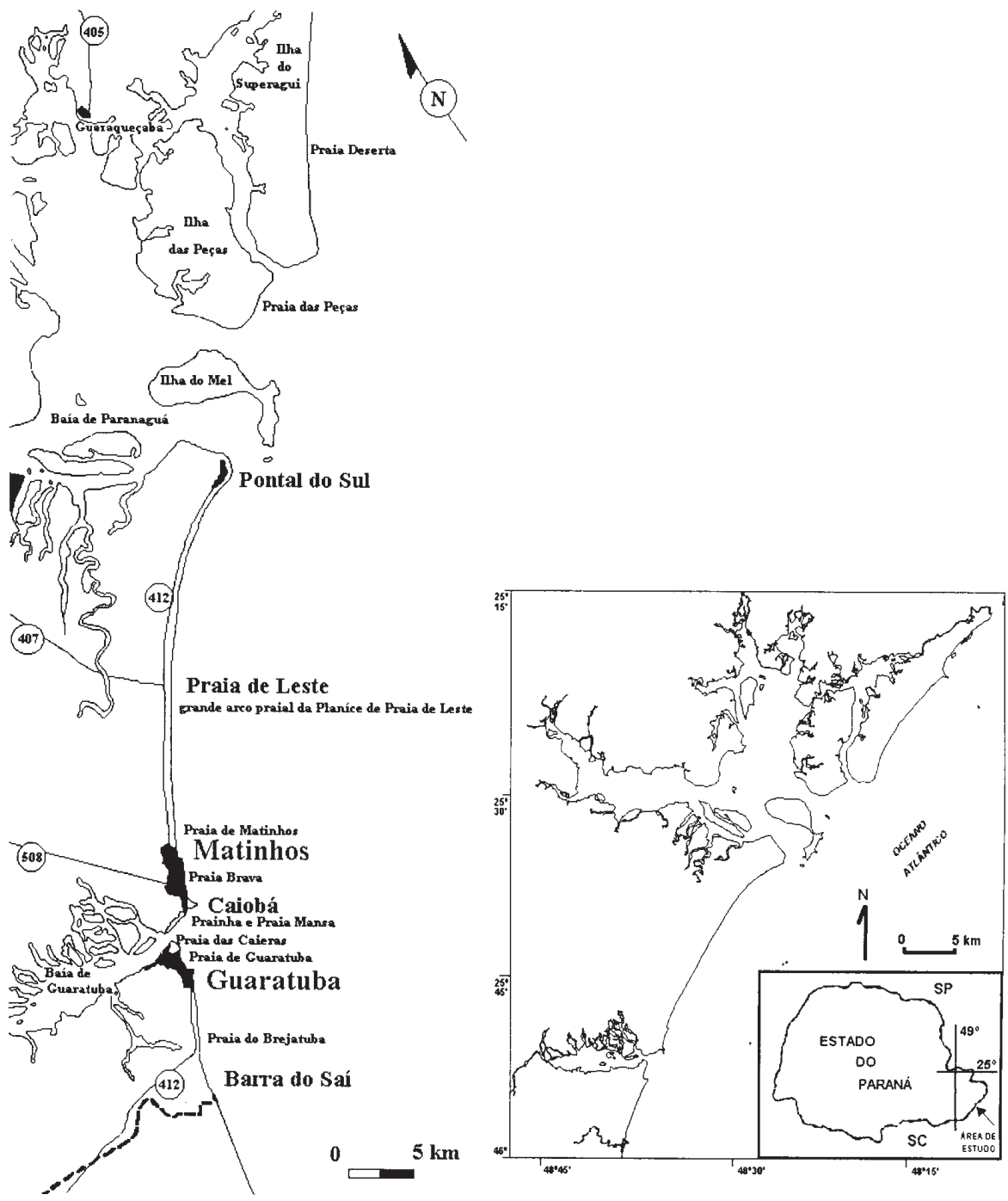

FIGURA 1 - LOCALIZAÇÃO DA ÁREA DE ESTUDO. Fonte: SOARES et al. (1997)

O litoral paranaense abriga um mosaico de ecossistemas, com fragmentos significativos da Floresta Atlântica. A diversidade de habitats naturais presentes nas regiões estuarinas inclui restingas, manguezais, marismas de Spartina e costões rochosos (LANA, 2003, p. 316; MARONE et al., 2002, p. 4-6; PIRES et al., 2005).

A região apresenta uma população fixa de 250 mil habitantes e já registrou 1,5 milhão de pessoas durante as temporadas de 1995/1996 e 1996/1997 (MARONE et al., 2002, p. 4-6; SOARES et al., 1997, p. 5). Os municípios do litoral paranaense podem ser classificados da seguinte maneira: portuários (Paranaguá e Antonina), rurais (Morretes e Guaraqueçaba) e praiano-turísticos (Guaratuba, Matinhos e Pontal do Sul) (ESTADES, 2003, p. 26). Os Índices de Desenvolvimento Humano Municipal (IDHM) dos municípios litorâneos do Paraná são: Guaratuba: 0,764; 
Matinhos: 0,793; Pontal do Paraná: 0,788; Paranaguá: 0,718; Morretes: 0,755; Antonina: 0,770; Guaraqueçaba: 0,659 (PNUD, 2003).

Há no litoral do Paraná cerca de 60 vilas de pescadores, rurais ou urbanas, no interior da baía e nas frentes oceânicas. Essas vilas apresentam-se em todos os municípios do litoral (exceto Morretes), desde pequenos povoados exclusivamente pesqueiros, acessíveis somente por água, até bairros urbanos. No litoral sul, estas vilas foram desestruturadas, pelo menos fisicamente, pela expansão urbana (ANDRIGUETTO FILHO, 1999, p. 37-38).

\section{O arrastão de praia paranaense}

O arrastão de praia, ou lanço de praia ou cerco, pode ser caracterizado como uma pesca artesanal de pequena escala voltada para uma grande variedade de peixes costeiros adultos e juvenis, com a possibilidade de se concentrar em uma ou poucas espécies, dependendo da estação do ano. O tamanho da rede varia de acordo com a intenção de uso, mas é geralmente pequena em comparação com a extensão do cardume que se pretende capturar. Pode, no entanto, ter centenas de metros de comprimento e uma altura que se estenda do fundo à superfície. A operacionalização do arrasto pode ocorrer na costa oceânica ou em rios e tem uma configuração semicircular: a rede é levada em uma canoa a remo e percorre um caminho em forma de meia-lua, cercando o cardume de peixes até retornar à costa. É então puxada, por tração mecânica ou manual, em direção à terra por duas longas cordas atadas às extremidades da rede (ANDRIGUETTO FILHO, 1999, p. 232; BRAUDT, 1984, p. 392; CORRÊA et al., 1993, p. 34-41; GRAY; KENELLY, 2003, p. 407; HAYES, 1985, p. 140; McCONNEY, 2003, p. 10, 13).

O arrastão de praia é uma forma antiga e tradicional de pesca artesanal no litoral do Paraná, sul do Brasil. Apresenta pouca expressão econômica, mas subsidiou a existência das famílias litorâneas por muitas gerações. Essa pesca tem como principal espécie-alvo a tainha (Mugil liza e Mugil platanus), de ocorrência sazonal nos meses mais frios, de meados de maio até meados de julho. Também é na "safra da tainha" que as particularidades do arrastão de praia mais se manifestam ou mais são percebidas, tais como divisão de tarefas, participação da comunidade em geral e maior participação das mulheres, além da competição ou cooperação entre os pescadores. Atualmente, os arrastões de praia de verão e os lanços de tainha encontram-se em franco declínio, ou mesmo em vias de extinção, no litoral do Paraná. Muitas comunidades já não praticam mais os arrastões, sequer na safra da tainha. Por outro lado, a continuidade da prática em algumas comunidades, apesar das marcadas transformações, evidencia que os elementos da permanência convivem com essa situação de declínio.

As entrevistas mostraram que o uso do motor, do náilon plástico e dos panos de redes prontos otimizaram as estratégias tradicionais de captura. Os novos apetrechos e estratégias de captura, quase sempre oriundos de Santa Catarina, foram fortemente condicionados pela demanda do mercado. O tempo empregado na pesca do arrastão de praia foi reduzido e os atuais pescadores não estão mais voltados exclusivamente para atividades extrativistas ou para a pequena agricultura, pois têm outras fontes de renda. A compra de apetrechos prontos (e.g. redes de náilon, remo, boias de isopor, no lugar de confeccionar as redes, os remos e as cortiças com materiais naturais) também reduziu ou modificou o tempo alocado para a atividade, permitindo o ócio (com a acepção de folga, repouso, tempo para descanso) ou o emprego do tempo em outras artes de pesca. Por outro lado, as roças e a produção de farinha, que junto com o arrastão de praia figuravam como meios de vida (alimentação, venda e troca), praticamente deixaram de existir.

As funções ou nichos nesse trabalho e o modelo de partilha pouco se alteraram ao longo do tempo e pouco variam entre as comunidades estudadas. Mesmo assim, o arrastão de praia conta com recursos humanos cada vez mais escassos e menos especializados, fato que diminui a possibilidade de boa produção. $\mathrm{O}$ arrastão de praia perdeu mão de obra para as pescas artesanais motorizadas, que são mais compensadoras financeiramente, pois a produção e rendimentos destas artes concentram-se em dois ou três tripulantes e o quinhão, portanto, é maior.

É considerada pelos pescadores uma prática socializadora, pois reúne crianças, jovens, mulheres e velhos, inclusive de outras comunidades, mas privilegia os pescadores locais. $\mathrm{O}$ trabalho da mulher é relevante e amplamente reconhecido, mas também implica dupla, se não tripla, jornada de trabalho. No passado, o arrastão de praia era associado a laços de parentesco e vizinhança, bem como cooperação. Hoje evidencia a competição, a "ganância" e o desmantelamento dos valores sociais, pois contrasta com as pescas modernas principalmente sob dois aspectos:

a) o arrastão de praia ainda aplica o sistema do terço: uma parte dos rendimentos é destinada à rede (ou seja, paga 
ao seu proprietário, para a manutenção dos apetrechos de pesca) e duas partes para os pescadores, considerando suas atribuições no arrastão. Já as pescas motorizadas fazem uma partilha mais desigual: embora pareça mais igualitária (meio a meio, às vezes descontando o combustível), ela concentra o recurso em poucas pessoas;

b) o arrastão de praia ainda mantém o código do respeito (regras locais de uso e apropriação dos recursos), mas os concorrentes, especialmente os amadores, não têm esses costumes e os pescadores jovens nativos nem sempre desenvolvem as condutas sociais antes consideradas importantes. Predominam os hábitos alóctones, pois não há mecanismos tradicionais que possam frear os novos padrões de consumo, estilos de vida e relação com a natureza. As pescas "mais simples" (feiticeira, cambau e tarrafa, que necessitam de redes baratas e de fácil uso) permitem a infiltração de não pescadores e alóctones que competem pelo mesmo recurso e, pior, não aprenderam e sequer respeitam as regras locais.

Segundo os informantes, o desinteresse pelo arrastão de praia foi motivado principalmente pelo declínio dos estoques de peixe e/ou afastamento dos cardumes da costa e pelas alternativas de trabalho e renda. Muitas espécies desapareceram ou são raramente capturadas na pesca artesanal em geral, indicando, pela visão emicista, uma sobrepesca. A diminuição dos peixes, entretanto, não se deve ao fim do respeito, que mais regulava o acesso equitativo do que o estoque de peixes. A diminuição dos peixes está mais relacionada à exploração do mar, à captura de juvenis, ao excesso de redes e ao emprego de malhas diminutas. $\mathrm{O}$ declínio dos estoques também foi relacionado ao excesso de pescadores em outras artes (pesca artesanal geral). Por outro lado, há um consenso entre os informantes de que a praia e os recursos são bens de livre acesso a todo cidadão, mas que a lógica da apropriação dos recursos deveria privilegiar as pessoas que vivem exclusivamente da pesca.

A comercialização do pescado capturado pelo arrastão de praia modificou-se com os eventos econômicos e sociais ocorridos com o passar do tempo. Num primeiro período, o peixe era seco (cambira) para consumo e troca por produtos não produzidos na comunidade. Seu comércio era muito restrito, já pelo difícil acesso rodoviário aos vilarejos e pela inexistência de resfriamento e estocagem. Faziam-se viagens, que duravam até três dias, em canoa a remo até Antonina ou Paranaguá, para vender nos mercados desses núcleos urbanos, mas o consumo era pequeno e as perdas, elevadas. Com a chegada do transporte por caminhão ao longo das praias, os pescados eram vendidos in natura e em grandes quantidades. Depois, à medida que as estradas iam sendo construídas, o acesso de atravessadores, turistas e veranistas foi facilitado, ampliando a demanda. Ultimamente os atravessadores percorrem as praias em caminhonetes ou buggies e compram o peixe recém-pescado. Atualmente, muitos pescadores munidos de gelo e freezer podem estocar e negociar preços com os atravessadores ou empresas de pesca, ou mesmo diretamente ao consumidor, obtendo uma renda um pouco maior. Mesmo assim, a dependência dos negociantes intermediários se evidencia nos períodos de baixa temporada ou quando maiores quantidades são capturadas e o escoamento da produção pelo varejo torna-se difícil. No entanto, não foram identificados, nas observações de campo e entrevistas, conflitos entre pescadores do arrastão de praia e atravessadores, possivelmente porque predominam as relações de amizade e parentesco.

Não foi atribuída pelos pescadores e ex-pescadores uma sobre-exploração pelo arrastão de praia, como se supôs na primeira hipótese de trabalho. O modo de conservação local remete a outras práticas: segundo os informantes, o arrastão de praia não é predatório; já outras práticas, como a pesca industrial e o arrasto de camarão, foram consideradas as causadoras da diminuição dos estoques, em razão da sobrepesca e da exploração de peixes juvenis. Os próprios informantes que hoje fazem o arrasto de camarão fizeram essa constatação.

No entanto, mais do que uma ética ambiental, havia um senso de conservação mais voltado para a economia (manutenção dos estoques para o arrastão de praia significava continuar capturando). Pelo que se apreende dos discursos dos pescadores, não havia objetivos conservacionistas no manejo tradicional, mas este mesmo sistema hoje admite tal objetivo. Uma mentalidade conservacionista ("neoconservação") surgiu muito recentemente, em decorrência do apelo ambientalista que orienta a segunda metade do século XX e o século XXI e das constatações empíricas de redução de peixes e da sua provável relação com as alterações ambientais. Essas constatações empíricas referem-se à percepção dos próprios pescadores sobre a redução do tamanho e da quantidade de peixes.

Em resumo, a prática do arrastão de praia é mais conservacionista, enquanto outras pescas são mais destrutivas, embora haja, de modo geral, o reconhecimento sobre a necessidade de conservação dos estoques. 


\section{Declínio e permanência do arrastão de praia paranaense}

A inserção de novas tecnologias de pesca mais produtivas e rentáveis contribui para as mudanças nos regimes de acesso aos recursos. Essas mudanças nos regimes de acesso aos recursos se caracterizam pelo desrespeito às regras informais de uso, o que tem provocado conflitos iminentes e pouco iminentes entre praticantes do arrastão de praia e praticantes de outras pescas. Esses conflitos dizem respeito principalmente às disputas pelos territórios de pesca e às técnicas e apetrechos que prejudicam a captura dos arrastões de praia. As novas tecnologias, por sua vez, apresentam maior produtividade; como são práticas individuais ${ }^{3}$ ou para até três pescadores, o quinhão é melhor. Em razão disso, essas pescas "roubam" a mão de obra dos arrastões de praia. Alguns pescadores entendem o sucesso das práticas individuais como um reflexo da "ganância", associando-o à "injustiça", pois o arrastão tradicional de praia é uma pesca coletiva e alimentaria, portanto, várias famílias.

As mudanças nos regimes de acesso aos recursos pesqueiros, por sua vez, promoveram ou favoreceram o declínio dos arrastões de praia. A modernagem, entendida como as profundas modificações socioambientais - como o aumento populacional, o turismo ${ }^{4}$, a inserção de novos apetrechos e técnicas e o aumento do número de pescadores alóctones e que não vivem exclusivamente da pesca - desenvolveu uma ruptura de valores, gerando o fim do respeito e uma cultura do acúmulo e do consumo, fomentando a competição, que se reflete no aumento do esforço de pesca, na preferência por práticas individuais, no uso de apetrechos considerados predatórios e na pesca em regiões e períodos proibidos.

Com o declínio do respeito, o excesso de pescadores, predominantemente não profissionais, e os impactos socioambientais do turismo, os recursos e os espaços passaram a ser percebidos pelos pescadores como de livre acesso a qualquer cidadão, quando na verdade são de propriedade do Estado, que concede ou não seu uso, segundo normativas preestabelecidas. Essa percepção, somada à descrença pelas regras formais e à crença de que o respeito não se restabelecerá e de que nem os órgãos governamentais têm poder para frear a desordem no setor pesqueiro, promove a perda da clareza sobre direitos e deveres, gerando uma atitude de conformismo e de perda da prática cultural, dificultando também a mobilização social pela luta dos direitos quanto ao acesso aos recursos pesqueiros.

Mesmo diante desse quadro pessimista, os usuários sugerem medidas de manejo, algumas utópicas e outras viáveis. Uma das sugestões foi a eleição de alguns pescadores da comunidade para acompanhar os fiscais nas autuações, sabendo distinguir os apetrechos de pescadores profissionais. O direito comparado permite nomear um guardião (trustee) da natureza, encarregado da sua proteção e da sua gestão judiciosa, em beneficio do público presente e futuro (OST, 1995, p. 352). Esses guardiões poderiam ser os próprios pescadores, participantes do comanejo, inclusive da aplicação de fiscalização e sanções.

Apesar da redução dos estoques, dos rendimentos e do número de pescadores, a pesca da tainha continua uma prática viva em vários pontos do litoral sul e sudeste, principalmente no Estado de Santa Catarina, possivelmente porque essa espécie faz reviver os valores comunitários e a identidade dos pescadores (DIEGUES, 2004, p. 303, 305). Seria interessante compreender por que em Santa Catarina ainda há maior participação no arrastão de tainha. É possível que haja nesse Estado uma melhor percepção dos direitos, implicando maior resiliência social.

Segundo Andriguetto Filho (1998, não publicado), os pescadores de Pontal do Sul e Pontal 2 (comunidades localizadas no município de Pontal do Paraná) estimaram, já em 1997, que o arrastão de praia acabaria em definitivo nesses locais em um ou dois anos. Isso não ocorreu nessas duas comunidades até o presente, apesar da sensível redução da prática, o que permite retomar o pressuposto inicial deste trabalho: certamente o conhecimento tradicional e as representações não materiais, associados à prática do arrastão, são, para os pescadores mais velhos, mais importantes do que os benefícios econômicos, o que manteria, ainda que em colapso, a prática do arrastão de praia no litoral su-sudeste do Brasil.

Diante disso e das observações de campo, talvez a melhor indagação não seja "por que a pesca do arrastão de praia está em declínio", mas "por que essa atividade ainda se

\footnotetext{
3 Apesar de atualmente a maioria das pescas artesanais serem realizadas em pares ou em trios, ao denominar pesca individual enfatizamos essa distinção ao comparar com o arrastão de praia, que é uma pesca coletiva, envolvendo várias famílias.

${ }^{4}$ Segundo Rebouças et al. (2006, p. 91), o turismo de massa fomenta o crescimento descontrolado da especulação imobiliária, ocupações e construções irregulares, tráfico de drogas, transformações negativas dos costumes, das visões de mundo e dos modos de vida tradicionais. Essas transformações implicam, portanto, impactos ecossistêmicos e sociais.
} 
mantém, ou por que alguns pescadores continuam praticando os arrastões de praia". Algumas possíveis respostas são:

a) Por identidade cultural e continuidade. O pescador extrai da pesca um significado para sua vida como caçador predador; ser dono de rede e/ ou quinhoeiro permite continuar o ofício de seus ancestrais. Além desse simbolismo e desse reforço de identidade cultural, os pescadores são também, segundo Godio (2005), atraídos pela luta simbólica com a tainha, cujos cardumes passam em grandes quantidades, mas nunca são de todo capturados;

b) Por necessidade alimentar/econômica. Ainda que a produção seja pequena, o "lanceio de almoço" permite a ingestão de proteína. Segundo um dos informantes de Pontal do Sul, de 86 anos de idade na época, quando a pescaria não rende nenhum peixe, precisa ir ao mercado comprar alimentos;

c) Por serem desprovidos de apetrechos para a pesca oceânica. Motor e canoa de fibra são equipamentos caros e nem todos pescadores têm capital ou se arriscam em empréstimos;

d) Por serem velhos, sem muita disposição física. Pela idade, não apresentam mais tanta disposição para trabalhos e riscos em mar aberto;

e) Por não encontrarem nicho em outros setores. Não têm a escolaridade exigida pelo mercado de trabalho ou outras oportunidades de emprego;

f) Por preservação e atualização do pertencimento a um grupo. A coletividade, que envolve diálogo, acordos, reunião, especialmente na safra da tainha, que marca uma ciclicidade na pesca, dá a cada um a noção de pertencimento e demarca a identidade do grupo. Essa noção de pertencimento, por sua vez, induziria ao bem-estar individual.

Essas respostas amenizam o caráter factual de declínio do arrastão de praia e enfatizam a existência de estratégias que têm garantido a sua permanência. Contudo, a pesquisa demonstrou que é necessária e urgente a realização de medidas de gestão pesqueira que evitem o colapso da arte ou revitalizem-na.

\section{Delineamentos para uma gestão integrada da pesca de pequena escala: alguns exemplos do arrastão de praia}

Os elementos mais relevantes para a gestão de pescas de pequena escala, com base na gestão patrimonial do arrastão de praia paranaense e nos pronunciamentos de Berkes (1984), Berkes et al. (2006), Cordell (2001), Lana (2003), Martin e Lana (1994), são considerados a seguir:

a) A informação científica deve ser prestada para $o$ comanejo da pesca, mas o gestor também precisa dialogar com os saberes e práticas locais;

b) $\mathrm{O}$ ordenamento pesqueiro da tainha na região sudeste e sul do Brasil precisa ser definido com base nas regras tradicionais de uso (respeito). Portanto, deve ser pensado regional ou localmente, considerando as peculiaridades e os contextos de cada realidade que busca normatizar. O diálogo entre gestão comunitária e gestão pública é um dos tópicos mais importantes e deve ser muito considerado se os órgãos gestores não pretendem que as formas de pesca mais simples e presumivelmente as menos impactantes (como o arrastão de praia, a tarrafa, o anzol e linha, e o espinhel) se extingam;

c) Há necessidade de tornar os atores da pesca artesanal paranaense voltados para a gestão participativa e empoderadora. Os atores envolvidos na pesca artesanal paranaense precisam alcançar consenso sobre os objetivos de gestão pesqueira. Segundo Berkes et al. (2006, p. 2324, 224, 257), os interesses comuns e o envolvimento dos atores, bem como a gestão botton-up, são a base para a negociação ou consenso. Para tanto, além do empoderamento, a gestão deverá dar subsídios para a união entre os pescadores, a fim de fortalecer o grupo e torná-lo mais apto para o comanejo, ao invés de investir em ações paternalistas. A discussão do tema da união exige, em primeiro lugar, a discussão do papel das colônias de pesca, que atualmente são vistas como meros despachantes, sem poder de adesão e tampouco de gestão. Não têm um papel sindicalista ou de porta-voz e não refletem as necessidades e vontades de seus associados. As Colônias deveriam ser revitalizadas com base no objetivo de empoderamento do grupo;

d) Para uma melhor representatividade das pescas marginais, como arrasto de praia, linha e anzol, tarrafa e 
espinhel, sugere-se que as reuniões para o ordenamento pesqueiro contem com a participação dos pescadores dessas práticas, e não apenas presidentes das colônias e federações que, muitas vezes, desconhecem as pescas de pequena escala, têm interesses em pescas de maiores resultados, além de, por vezes, colocarem interesses pessoais à frente dos interesses coletivos. Há vários grupos contrastantes dentro do setor e alguns não são privilegiados, porque os representantes eleitos as ignoram ou não têm interesse econômico ou político sobre eles;

e) Manter a própria comunidade pesqueira já é parte do objetivo da gestão da pesca. A revitalização do arrastão de praia, tanto lanços de tainha como de peixes de fundo, implica a manutenção da sociodiversidade, um dos temas contemplados pela Convenção da Diversidade Biológica e que deve ser incorporado pela gestão pesqueira.

Apesar dessas necessidades, segundo Berkes et al. (2006, p. 22), é improvável que governantes de países em desenvolvimento gastem recursos nos meios convencionais de pesquisa e gestão da pesca de pequena escala, porque essa pesca costuma ser vista como uma rede de segurança social, um aspecto cultural e uma fonte de emprego para pessoas menos habilidosas ou educadas, e não como um dos mecanismos primários da economia. Convém frisar que esse pronunciamento de Berkes e colaboradores critica a visão preconceituosa que o governo ou a sociedade urbano-industrial em geral tem sobre esses trabalhadores.

Ademais, no Brasil predomina um estilo de gestão centralizado e tecnocrático (executado pelo governo) muito aquém do sistema integrado. As intervenções do poder público continuam tendo um forte viés economicista-produtivista, com ênfase para a expansão e a modernização tecnológica da pesca industrial (KALIKOSKI et al., 2002, citados por REBOUÇAS et al., 2006, p. 91). Os esforços para a integração da pesca com outros setores (agrícola, agroindustrial, industrial, turístico, portuário, de transportes) em prol do desenvolvimento das comunidades de pescadores artesanais são ainda muito incipientes (REBOUÇAS et al., 2006, p. 92).

A literatura disponível demonstra que a gestão centralizada dos comuns tende a privilegiar grupos econômicos poderosos [e.g. pesca industrial] e a aumentar a vulnerabi- lidade dos sistemas socioecológicos (REBOUÇAS et al., 2006, p. 94), incluindo a vulnerabilidade das instituições tradicionais (regras de uso). A globalização assimétrica favorece a exploração desordenada e polarizada pela busca de acumulação de lucros no curto prazo, fortalecendo a ascensão de grupos hegemônicos, como a pesca industrial em detrimento da pesca artesanal (REBOUÇAS et al., 2006, p. 84).

Por outro lado, e diante das recomendações supracitadas para a gestão pesqueira, é importante ressaltar o interesse do IBAMA pela pesca artesanal da tainha, pelas artes de subsistência, pela continuidade da tradição e pelos aspectos de cooperação e coletividade envolvidos nos arrastões de praia, como se pôde perceber na "Reunião Técnica para o Ordenamento da Pesca da Tainha na Região Sudeste/Sul do Brasil", promovida pelo CEPSUL/IBAMA no período de 24 a 26 de abril de 2007, em Itajaí, Santa Catarina. Esse interesse pode ser ampliado com a divulgação de pesquisas acadêmicas que envolvam comunidades pesqueiras de pequena escala e suas formas de uso e apropriação dos recursos naturais. Emerge daí o papel da Universidade para a divulgação, às agências governamentais e gestores, dos resultados que vem obtendo e do que a literatura mundial tem demonstrado.

Convém salientar que para o caso da pesca do arrastão de praia no sul do Brasil, incluindo tanto os lances de verão como de tainha, é importante diferenciar artes motorizadas e não motorizadas. A diversidade de atividades pesqueiras dificulta definir o que é industrial, comercial ou artesanal ${ }^{5}$ e, para fins de manejo e normatização do arrastão de praia, é importante distinguir pesca artesanal motorizada e não motorizada, dadas as suas diferenças nos seus sistemas social e de produção. Também é essencial considerar as diferenças e semelhanças das características ambientais e sociais entre diferentes comunidades pesqueiras. Alguns estudos acadêmicos e, principalmente, os gestores e órgãos governamentais tendem a generalizar as realidades pesqueiras. É importante considerar as peculiaridades, o que implica necessidade de estudos locais para quaisquer medidas de manejo.

O arrastão de praia pode ser considerado, como descreveu um pescador da praia do Campeche, em Floria-

\footnotetext{
${ }^{5}$ A grande diversidade de formas de organização e produção na pesca artesanal é evidenciada por um extremo de grande escala (comercial/industrial) e um extremo de pequena escala (comercial, artesanal, subsistência) (BERKES et al., 2006, p. 26). No litoral do Paraná, parece mais adequado dispor o conjunto de práticas pesqueiras num gradiente contínuo de um extremo claramente artesanal, ou mesmo de subsistência, a um claramente empresarial, sem se procurar traçar um limite (ANDRIGUETTO FILHO, 1999, p. 186). A pesca de pequena escala inclui pescarias tradicionais, artesanais e de subsistência, sejam mecanizadas ou que usem pequenas redes, armadilhas, linhas, arpões ou coleta manual. Ocorre em comunidades rurais, com maior número de frotas e barcos explorando vários estoques pequenos, compondo várias unidades de gestão que necessitam, portanto, de vários planos de gestão (BERKES et al., 2006, p. 30-32).
} 
nópolis, a "pesca mãe" de todas as artes de pesca. Só por esse motivo, e pelo fato de ser uma pesca coletiva, que desenvolve laços sociais importantes para o espírito comunitário, como coletividade, colaboração, respeito às normas sociais, reunião e partilha, o arrastão de praia merece ser repensado e incorporado na agenda de preocupações dos órgãos gestores. Ademais, a importância cultural de uma pescaria pode lhe atribuir um valor muito maior que o seu valor econômico mensurado (BERKES et al., 2006, p. 73). Esse passo deverá ser tomado em conjunto com os usuários, levando em conta a história dessa prática e a projeção de cenários que os pescadores mais velhos conseguem fazer, baseados em suas experiências e nas profundas mudanças socioambientais (redução no tamanho e na quantidade de peixes, desaparecimento de espécies, poluição, desmantelamento cultural, desconstrução da paisagem, criminalidade, dentre tantos outros) que tiveram chance de observar. Conhecer crenças, sentimentos e comportamentos das diferentes gerações de pescadores frente à natureza pode auxiliar de fato no tão almejado desenvolvimento sustentável. Mas esse desenvolver-se sustentavelmente não pode ser feito à revelia da população que do peixe vive. As artes simples, de pequena produção, não podem ficar à margem dos planos de desenvolvimento local; os gestores parecem sempre interessados em resultados, em grandes produções. Nisso, a pesca de pequena escala no Brasil parece minguar. Nesse sentido, cabe citar Ost (1995, p. 390): "a injustiça das relações sociais gera a injustiça das relações com a natureza".

Sem gestão, a pesca tende a perder sua viabilidade econômica e a entrar em colapso. Isso está relacionado, na maior parte dos casos, com o drástico declínio dos estoques (BERKES et al., 2006, p. 33). No caso do arrastão de praia paranaense, outros aspectos entram em jogo: a maior rentabilidade das outras pescas, a existência de outros setores e nichos mais promissores e a dificuldade em conseguir mão de obra para a realização dos arrastões.

Considerando-se que pescas costeiras de pequena escala são mais vulneráveis a atividades alheias à pesca, os gestores e os atores precisarão de esforço mais para evitar e mitigar as influências externas do que para controlar o acesso (BERKES et al., 2006, p. 228-229). Isso se aplica perfeitamente ao caso do arrastão de praia no litoral paranaense, principalmente face à perda do respeito, incorrendo na formulação de outro problema de pesquisa e de gestão: verifica-se a necessidade de coesão entre os atores da pesca artesanal, principalmente entre os usuários. Essa "união" se dá a partir da informação, da afinidade de opiniões e do empoderamento dos usuários. Surge então a problemática maior, que talvez se aplique a todas as modalidades de pesca de pequena escala: como auxiliar as comunidades pesqueiras a evitar as influências externas, impactantes aos mecanismos internos e informais de regulação de acesso ao recurso? Essa indagação exige antes outras reflexões, como "quais influências precisam ser evitadas e por quê?".

Por exemplo, as relações sociais na pesca em Arembepe, no litoral da Bahia, tiveram um crescimento mais econômico do que social/humano no curto espaço de tempo entre 1973 e 1980. Não obstante, já pela ideologia da igualdade fortemente presente nessa comunidade, seus pescadores ressentem-se dessas mudanças. Muitos pararam de pescar, mas um inchaço de imigrantes ajudou a preencher esse vazio, formando outra discussão: a transformação da economia pesqueira local em uma economia pesqueira regional (KOTTAK, 2009, p. 5). Essa transformação reflete perfeitamente o modelo econômico regional e mundial vigente e implica também uma série de mudanças profundas e radicais nas relações entre humanos e entre humanos e natureza.

A crise decorrente da degradação dos recursos apresenta uma série de disfunções, tais como: os ecossistemas tornam-se mais frágeis e vulneráveis a surpresas e crises; as instituições de gestão tornam-se mais rígidas e pouco aptas a oferecer respostas às mudanças ecossistêmicas; as sociedades tornam-se mais dependentes das oscilações no contexto internacional (REBOUÇAS et al., 2006, p. 91, sem grifos no original). No caso do arrastão de praia paranaense, ficou claro que as instituições tradicionais de gestão (regras locais para os usos dos recursos) não se tornaram rígidas, mas sim frouxas a ponto de não serem mais reconhecidas pelos novos pescadores. Noutras palavras, as regras de uso colapsaram porque perderam o sentido face ao mercado agressivo e avassalador. A arte de pesca avaliada mostrou-se não só mais dependente das oscilações nacionais ou internacionais, como sugere o autor, mas sujeitas ao próprio contexto local e regional.

Manter as comunidades pesqueiras e envolvê-las no processo de gestão é a lógica da capacitação, mas nem todas as comunidades têm condições de criar suas próprias regras (BERKES et al., 2006, p. 256) e é atribuição da gestão pesqueira desenvolver essa habilidade. Não se trata de dar o peixe, nem de ensinar a pescar. As regras para a pesca artesanal paranaense precisam ser recriadas com base na opinião dos próprios usuários, mas de todos os tipos de usuários (da pesca de subsistência à pesca artesanal comercial). As regras (respeito) que existiam no arrastão 
de praia poderiam ser modelos ou inspirações para esse empoderamento.

Tais questões suscitam as categorias de autonomia e heteronomia na pesca artesanal (REBOUÇAS et al., 2006, p. 95) e reafirmam a necessidade de transição de pensamento na gestão pesqueira.

Se antes o respeito era suficiente para regular o acesso à pesca de arrastão de praia e ao recurso, hoje ele já não é mais. Há necessidade da elaboração de regras formais (CORDELL, 2001), levando-se em conta a coexistência de dois códigos culturais: o código da economia de mercado e da competição/acumulação contrapondo-se ao código da solidariedade e da reciprocidade. O código da economia de mercado se tornou hegemônico e avassalador e redefiniu o código da solidariedade. No entanto, implica uma indagação complexa: será que ele garante a permanência? Por outro lado, é possível alcançar uma relação harmônica entre a lógica de mercado e a racionalidade do pescador?

Ficou claro que, no ambiente pesqueiro, ordem (respeito) e progresso (modernagem) são processos antagônicos, incompatíveis, a menos que uma gestão adequada conduza essas duas forças, que têm diferentes origens: rural - tradicional e conservadora - e urbana - moderna e agressiva -, respectivamente.

Diagnósticos semelhantes podem ser aplicados a outras partes do litoral brasileiro. Os avanços obtidos com a

\section{Referências}

Ab'SABER, A. N. Litoral do Brasil: pesquisa e texto. São Paulo: Metalivros, 2001.

ANDRIGUETTO FILHO, J. M. Interações, fatores de mudança e sustentabilidade das práticas materiais e dinâmicas ambientais nos sistemas técnicos da pesca artesanal do litoral do Paraná. Processamento de entrevistas, Pontal do Paraná. 1998. Texto não publicado.

. Sistemas técnicos de pesca e suas dinâmicas de transformação no litoral do Paraná, Brasil. Tese (Doutorado em Meio Ambiente e Desenvolvimento) - Universidade Federal do Paraná (UFPR) e Université de Bordeaux II. 255 p. + anexos. Curitiba, 1999.

BECK, A. Aspectos socioeconômicos da pescaria da tainha em Santa Catarina (Projeto Mugilidae): relatório de pesquisa. Florianópolis: Universidade Federal de Santa Catarina, 1989. Texto mimeografado. abordagem metodológica e conceitual e com a delimitação do problema de pesquisa indicam que a mesma abordagem pode ser usada em outras regiões, para a investigação de pescarias artesanais e das regras tradicionais e gestão patrimonial pesqueiras. Segundo Montgolfier e Natali (1997), Ollagnon (1997) e Vinatea (2000), a gestão patrimonial encerra em seu quadro conceitual e operacional a negociação eficiente entre os diferentes interesses envolvidos (atores individuais, coletivos e governamentais). Pode ser, portanto, um importante arcabouço teórico-metodológico para a gestão das pescas de pequena escala.

\section{Agradecimentos}

Agradecemos ao CNPq pela concessão da bolsa de doutorado à primeira autora; aos professores Renato Silvano, Raquel Negrelle, Paulo de Tarso Chaves, Marília Gomes de Carvalho e Karen Karam pela crítica nas ocasiões da qualificação e da defesa de tese; aos (ex-)pescadores e pescadoras do arrastão de praia do litoral do Paraná pela contribuição para a pesquisa mediante suas histórias de vida, narrativas, respostas aos roteiros de perguntas e pela oportunidade do aprendizado vivenciado.

BERKES, F. Competition between commercial and sport fishermen: an ecological analysis. Human Ecology, v. 12, n. 4, p. 413-429, 1984.

; MAHON, R.; McCONNEY, P.; POLLNAC, R.; POMEROY, R. (autores da versão original em inglês); KALIKOSKI, D. C. (Org. edição em português). Gestão da pesca de pequena escala: diretrizes e métodos alternativos. Rio Grande: Ed. Furg, 2006. 360 p.

BRAUDT, A. V. Fish catching methods of the world. $3^{\text {rd }}$ ed. Farnham: Fishing News Books Ltd., 1984.

CORDELL, J. Marginalidade social e apropriação territorial marítima na Bahia. In: DIEGUES, A. C.; MOREIRA, A. C. C. Espaços e recursos naturais de uso comum. São Paulo: NUPAUB-USP, p. 139-160, 2001.

CORREAA, M. F. M.; LEMOS, P. H. B.; AGUIAR, C. R. Z. A pesca artesanal da tainha no litoral do Estado do Paraná. 
Curitiba: Secretaria de Estado da Cultura: Universidade Federal do Paraná, 1993.

DIEGUES, A. C. S. A pesca construindo sociedades: leituras em antropologia marítima e pesqueira. São Paulo: NUPAUB-USP, 2004. $315 \mathrm{p}$.

ESTADES, N. P. O litoral do Paraná: entre a riqueza natural e a pobreza social. Desenvolvimento e Meio Ambiente, n. 8, p. 25-41, 2003.

GODIO, M. Quinhentos Quilos!: ensaio etnográfico sobre uma sociomontagem audiovisual com um grupo de trabalhadores da pesca na comunidade da Barra da Lagoa, Florianópolis. Dissertação (Mestrado em Antropologia Social) - Curso de Pós-Graduação em Antropologia Social, Centro de Filosofia e Ciências Humanas, Universidade Federal de Santa Catarina, Ilha de Santa Catarina. 149 p. 2005.

GRAY, C. A.; KENNELLY, S. J. Catch characteristics of the commercial beach-seine fisheries in two Australian barrier estuaries. Fisheries research, v. 63, p. 405-422, 2003.

HAYES, M. L. Active fish capture methods. In: NIELSEN, L. A.; JOHNSON, D. L. (Eds.). Fisheries techniques. $2^{\text {nd }}$ printing. Bethesda, Maryland: American Fisheries Society, 1985.

KOTTAK, C. The globalization of a Brazilian Fishing Community. Bulletin of the General Anthropology Division, v. 16, n. 1, p. 1-7, 2009 .

LANA, P. C. Manguezais, legislação e gestão de áreas costeiras: o caso da baía de Paranaguá. In: VIEIRA, P. F. (Org.) Conservação da diversidade biológica e cultural em zonas costeiras: enfoques e experiências na América Latina e no Caribe. Florianópolis: APED, p. 313-331, 2003.

MAACK, R. Geografia Física do Estado do Paraná. Curitiba: BADEP/UFPR/IBPT, 1968. 350 p.

MARONE, E. et al. Proposta técnica para o plano de manejo do parque natural municipal do rio Perequê. Pontal do Paraná: UFPR/FUNPAR/CEM/FOSPAR/ Prefeitura Municipal de Pontal do Paraná, 2002.

MARQUES, J. G. W. Pescando pescadores: ciência e etnociência em uma perspectiva ecológica. 2. ed. São Paulo: Núcleo de Apoio à Pesquisa sobre Populações Humanas e Áreas Úmidas Brasileiras, USP, 2001.

MARTIN, F.; LANA, P. C. Aspectos jurídicos relativos à proteção dos manguezais da Baía de Paranaguá. In: SIMPÓSIO DE ECOSSISTEMAS DA COSTA BRASILEIRA, 2., e SIMPÓSIO DE ECOSSISTEMAS DA COSTA BRASILEIRA, 3. Anais, v. 1, p. 107-112, 1994.
McCONNEY, P. Grenada case study: legalisation of beach seine tradicional rules at Gouyave. Barbados: Caribbean Coastal Co-management Guidelines Project. Caribbean Conservation Association, 2003. 70 p

MONTGOLFIER, J.; NATALI, J.-M. Instrumentos para uma gestão patrimonial. In: VIEIRA, P. F.; WEBER, J. (Orgs.). Gestão de recursos naturais renováveis e desenvolvimento: novos desafios para a pesquisa ambiental. São Paulo: Cortez, 1997.

NAZAREA, V. D. Introduction: A View From a Point: Ethnoecology as Situated Knowledge. In: NAZAREA, V. D. Ethnoecology: Situated Knowledge/Located Lives. The University of Arizona Press, p. 3-20, 1999.

OLLAGNON, H. Estratégia patrimonial para a gestão dos recursos e dos meios naturais: Enfoque integrado da gestão do meio rural. In: VIEIRA, P. F.; WEBER, J. (Orgs.). Gestão de recursos naturais renováveis e desenvolvimento: novos desafios para a pesquisa ambiental. São Paulo: Cortez, 1997.

OST, F. A natureza à margem da lei: a ecologia à prova do direito. Lisboa: Instituto Piaget, 1995.

PINHEIRO, L. O declínio da pesca de arrastão de praia face às mudanças nos regimes de uso e apropriação dos recursos pesqueiros no litoral do Paraná. Tese (Doutorado em Meio Ambiente e Desenvolvimento) - Pós-Graduação em Meio Ambiente e Desenvolvimento, Universidade Federal do Paraná. 277 p. Curitiba, 2007.

; LANA, P. C.; ANDRIGUETTO FILHO, J. M.; HANAZAKI, N. A pesca do arrastão de praia no litoral do Paraná: reflexões sobre o método etnoecológico. In: ARAÚJO, T. A. S.; ALBUQUERQUE, U. P. (Orgs.). Encontros e desencontros na pesquisa etnobiológica e etnoecológica: os desafios do trabalho em campo. Recife: NUPEEA, p. 145-163, 2009.

PIRES, P. T. L.; ZILLI; A. L.; BLUM, C. T. (Coord. Técnica). Atlas da Floresta Atlântica do Paraná. Curitiba: SEMA/Programa de Proteção da Floresta Atlântica - Pró-Atlântica, 2005.

PNUD. Atlas do Desenvolvimento Humano no Brasil. Software (® 2003 EM Consultoria; Dados ${ }^{\circledR} 2003$ PNUD. Versão 1.0.0. Disponível em: $<$ http://www.pnud.org.br/idh $>$.

REBOUÇAS, G. N.; FILARDI, A. C. L.; VIEIRA, P. F. Gestão integrada e participativa da pesca artesanal: potencialidades e obstáculos no litoral do Estado de Santa Catarina. Ambiente e Sociedade, v. IX, n. 2, p. 83-104, 2006.

SOARES, C. R.; ÂNGULO, J. R.; LESSA, G. C. Roteiro da excursão ao litoral do Estado do Paraná: morfodinâmica de ambientes atuais, evolução da planície durante o quaternário e problemas de erosão costeira.. In: CONGRESSO DA AS- 
SOCIAÇÃO BRASILEIRA DE ESTUDOS DO QUATERNÁRIO, 6. 27 jul. a 03 ago. 1997. Publicação especial n. 2. Curitiba: Associação Brasileira de Estudos do Quaternário, 1997.

TOLEDO, V. M. What is Ethnoecology? Origins, scope and implications of a rising discipline. Etnoecológica, v. 1, n. 1, p. 5-21, 1992.

VIEIRA, P. F. Gestão patrimonial de recursos naturais: construindo o ecodesenvolvimento em regiões litorâneas. In: CAVALCANTI, C. (Org.). Desenvolvimento e Natureza: estudos para uma sociedade sustentável. São Paulo: Editora Cortez; Recife: Fundação Joaquim Nabuco, p. 293-322, 1995.

Gestão de recursos comuns para o ecodesenvolvimento. In: VIEIRA, P. F.; BERKES, F.; SEIXAS, C. S. (Orgs.). Gestão integrada e participativa de recursos naturais: con- ceitos, métodos e experiências. Florianópolis: Secco/APED, p. 333-377, 2005.

; WEBER, J. Introdução geral: sociedades, naturezas e desenvolvimento viável. In: VIEIRA, P. F.; WEBER, J. (Orgs.). Gestão de recursos naturais renováveis e desenvolvimento: novos desafios para a pesquisa ambiental. São Paulo: Cortez, 1997.

VINATEA, L. Modos de apropriação e gestão patrimonial de recursos pesqueiros: estudo de caso sobre o potencial e os riscos do cultivo de moluscos marinhos na baía de Florianópolis, Santa Catarina. Tese (Doutorado) - Curso de Pós-Graduação Interdisciplinar em Ciências Humanas, Universidade Federal de Santa Catarina (UFSC). 245 p. Florianópolis, 2000.

Recebido em novembro de 2009. Aceito em junho de 2010. Publicado em dezembro de 2010. 